
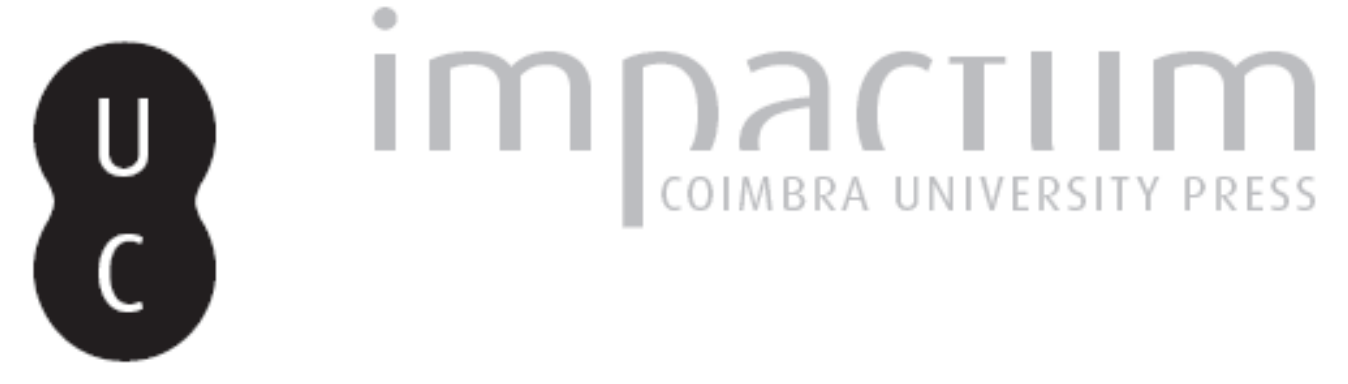

\title{
Dança, educação e antropologia: libertar o movimento
}

\section{Autor(es): Houart, Jacques}

Publicado por: CIAS - Centro de Investigação em Antropologia e Saúde

URL persistente:

URI:http://hdl.handle.net/10316.2/41237

DOI:

DOI:http://dx.doi.org/10.14195/2182-7982_17_1

Accessed : $\quad$ 26-Apr-2023 16:34:43

A navegação consulta e descarregamento dos títulos inseridos nas Bibliotecas Digitais UC Digitalis, UC Pombalina e UC Impactum, pressupõem a aceitação plena e sem reservas dos Termos e Condições de Uso destas Bibliotecas Digitais, disponíveis em https://digitalis.uc.pt/pt-pt/termos.

Conforme exposto nos referidos Termos e Condições de Uso, o descarregamento de títulos de acesso restrito requer uma licença válida de autorização devendo o utilizador aceder ao(s) documento(s) a partir de um endereço de IP da instituição detentora da supramencionada licença.

Ao utilizador é apenas permitido o descarregamento para uso pessoal, pelo que o emprego do(s) título(s) descarregado(s) para outro fim, designadamente comercial, carece de autorização do respetivo autor ou editor da obra.

Na medida em que todas as obras da UC Digitalis se encontram protegidas pelo Código do Direito de Autor e Direitos Conexos e demais legislação aplicável, toda a cópia, parcial ou total, deste documento, nos casos em que é legalmente admitida, deverá conter ou fazer-se acompanhar por este aviso.

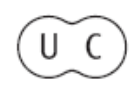




\section{Antropologia Portuguesa}

$16-17 \cdot 1999-2000$

Departamento de Antropologia | Universidade de Coimbra 


\title{
Dança, educação e antropologia: libertar o movimento
}

\author{
Jacques Houart
}

Departamento de Antropologia

Universidade de Coimbra

3000-056 Coimbra, Portugal

jacquesh@ci.uc.pt

\section{Resumo}

O que atrai na antropologia actual é uma metodologia mais atenta ao corpo, ao vivido, ao emocional. Ela reencontra, neste terreno, a evolução da dança contemporânea e as suas tentativas de libertar o movimento e a expressão. De uma aproximação entre os dois domínios resultam novas perspectivas sobre a edacação, sobre o ensino e sobre o saber. Já não se trata de domar os corpos para methor alimentar os espíritos, mas sim de promover, simultaneamente, o desibrochar cognitivo, afectivo e convivial. São as formas institucionais do poder, e o seu enraizamento social, que é preciso entāo questionar.

\section{Palavras-chave}

Dança, educaçāo, antropologia, poder

\section{Résumé}

Ce qui attire dans l'anthropologie actuelle, c'est une méthodologie plus attentive au corps, au vécu, à l'émotionnel. Elle retrouve, sur ce terrain, l'évolution de la danse contemporaine et ses tentatives de libération du mouvement et de l'expression. D'un rapprochement entre les deux domaines, résultent de nouvelles perspectives sur l'éducation, l'enseignement et le salvoir. Il ne s'agit plus de dompter les corps pour mieux alimenter les esprits, mais de promouvoir, simultanément, l'épanouissement cognitif, affectif e convivial. Ce sont les formes institutuionnelles du pouvoir, et leur enracinement social, qu'il faut alors questionner,

\section{Mots-clefs}

Danse, éducation, anthropologie, pouvoir 
Para Denis Diderot, a dança é poesia. E é o que ela é, sob algumas condições no entanto, porque a dança, sem mais, não é um remédio sem falhas para a ausência de criatividade na vida. Mas a dança que é poesia, e que, sendo poesia, surge do mais profundo dos nossos impulsos vitais, constitui, ela sim, uma experiência primordial a inscrever, como momento privilegiado, em qualquer processo educativo. No entanto, não é isso que acontece actualmente, em geral, na educação e no ensino. Apesar das investigaçōes e realizações recentes no domínio da dança, que visam provocar a libertação do movimento e a subsequente potencialização de todas as capacidades humanas - afectivas, cognitivas, conviviais -, os nossos sistemas educativos continuam impregnados de preconceitos civilizacionais' que impedem o pleno desenvolvimento e a completa maturação da personalidade humana e do seu sentido social. Procuremos as razões desta situação.

Segundo Pierre Lory (1999), somos os herdeiros de uma tradição que procura neutralizar as pulsões físicas, dar prioridade à apreensão conceitual dos fenómenos e manter a exterioridade do observador em relação ao seu objecto. Deste modo entende-se melhor, agora, a procura crescente da antropologia, sobretudo a partir dos anos 1970. Como o explica Albert Doutreloux - citado por Jacques Lombard (1984), num trabalho em que estabelece um balanço comparativo do ensino da antropologia em vários países -, mais do que a obtenção de um conhecimento preciso, é o desejo, muitas vezes assaz confuso, aliás, de um distanciamento em relação à sua própria sociedade, e de um enriquecimento cultural e humano no contacto com sociedades menos anónimas do que as nossas, que constituiria

${ }^{1}$ Numa obra ficcional, mas nutrida de conceitos científicos, La Grande Implosion, Pierre Thuillier (1995), procurando as causas do colapso do nosso modelo de civilização, no abandono a que o ideal poético foi votado, interrogi-se sobre as razōes pelas quais, depois de tantos avisos de pessoas cultas, inteligentes, racionais, científicas, em que tudo foi dito sobre as manifestaçōes exacerbadas do culto do progresso, os delírios da gestão tecnocrática, o poder sem limites das instituiçoes económicas e financeiras, a ânsia obsessiva de riqueza, poder, prestígio, a falta de imaginaçāo, sensibilidade e calor humano dos políticos, os exageros do individualismo e do narcisismo, o agravamento dos desequilíbrios entre o Norte e o Sul, entre os mais ricos e os mais pobres, os ocidentais se obstinaram nos seus hábitos destrutivos. E conclui que continuaram convictos de que o seu modo de vida representava a incarnação definitjva da Civilização. 
uma das razões principais do actual sucesso da antropologia. Alfred Métraux, quando define a personalidade básica do antropólogo, em termos um tanto provocadores, não diz outra coisa: a maior parte dos antropólogos são pessoas rebeldes, ansiosas, que não se sentem à vontade na sua própria civilização, e que consideram que outras culturas conseguiram resolver, infinitamente melhor do que a nossa, os problemas que se colocam ao ser humano.

A metodologia antropológica, a partir de Franz Boas, e sobretudo de Bronislaw Malinowski, em grande parte determinada pelas características do objecto empírico que considerava seu - sociedades longínquas, de pequena dimensão e de tradição oral -, veio reforçar ainda mais o interesse recente pelos trabalhos dos antropólogos. Muito mais do que uma metodologia quantitativa, trata-se de uma abordagem qualitativa, em ruptura com qualquer modo de conhecimento abstracto especulativo², e que se baseia na observação directa dos comportamentos sociais a partir de uma relação humana. São a experiência de imersão completa na cultura que se estuda, a vivência como momento constitutivo do processo de conhecimento, a procura do saber transformada numa viagem exótica e iniciática, que tornam a antropologia tão atraente. A antropologia já não pretende, portanto, ser uma ciência exacta, no sentido absoluto e definitivo do termo, ao qual foi circunscrita no início da sua história, pelo paradigma da modernidade. Até porque este modelo de ciência, por ter querido esvaziar a procura da verdade do momento incontornável das escolhas subjectivas e da assunção das responsabilidades sociais, redundou numa crise do pensamento de que, ainda hoje, não conseguiu sair.

É aqui que a antropologia da dança, ou etnocoreologia - termo forjado recentemente à semelhança da palavra etnomusicologia (a palavra "música" vem, aliás, do grego musikê, arte das musas, que incluia, nos antigos Gregos, a música, a dança e a poesia, - se transforma num dos lugares estratégicos dos debates contemporâneos no domínio epistemológico, e das questões relativas ao ensino da antropologia, e ao ensino tout court.

2As primeiras grandes teorizaçōes antropológicas, evolucionistas, nāo escaparam a este desvio especulativo dos "antropólogos de gabinete". 
É a conclusão que resulta das afirmações de Pierre Legendre (2000) quando nos lembra que a dança é a forma mais animal, mais convulsiva (retomando uma palavra do vocabulário surrealista) do que chamamos a arte. E Legendre questiona: não terá sido a dança o ponto focal, o lugar incandescente, a partir do qual tudo irradiou e se diferenciou em ritmos musicais, em valores plásticos do movimento, ou seja, em pinturas, esculturas, escritas, em todas estas manifestações enigmáticas da vida que só pertencem ao ser humano? É que estas montagens da dança, em que o ser humano fala com as mãos, com os pés, com o corpo, em movimento à volta de si mesmo, da sua imagem e da imagem do mundo, nos obrigam, a nós, ocidentais, presos ao fetichismo da fria objectividade ${ }^{3}$, a enfrentar o grande caos das pulsões, das imagens e do desconhecido de onde emerge o ser poético. Para Legendre, é aqui que falhamos.

Daî a importância, nas nossas sociedades de gestão, coisificação e manipulação do corpo $c$ do espírito, de destituição dos daimônes como fontes mais essenciais de inspiração, e de encarceramento dos deuses dos outros nos museus - museus profundamente carentes das suas musas, e que Michel Leiris comparava, aliás, aos bordéis -, em estabelecer a genealogia deste recalcamento progressivo, pela sociedade ocidental, do corpo, da sensibilidade, da paixão, do calor humano. Não se trata, aqui, de contrapor o irracional ao racional como instância decisória das nossas escolhas de vida, mas sim de evitar, pela ignorância da sua origem e dos seus eleitos, e da sua importância no nosso imaginário, o ressurgimento do recalcado em formas de violência extremas, e extremamente destrutivas, que já ninguém consegue controlar.

As nossas sociedades têm de andar à procura do tempo perdido: um tempo que era para "perder" no prazer, na meditação, na oração, tempo esse que se perdeu ao mesmo tempo que se perderam os espaços que o proporcionavam. Tempos e espaços com os quais se perderam, também, as nossas capacidades poéticas, e que se trata, agora, de reinventar, de

'Caracterizando a escuizofrenia como uma psicose étnica, Georges Devereux, nos seus Essaris d'ethopsychiatrie générale (1972) considera o ideal científico da fria objectividade como um desses modelos escuizóides, característicos das nossas sociedades e, portanto, valorizados e activamente alimentados pela civilizaçāo moderna. 
reconfigurar, em formas originais, afim de os tornar, de novo, propícios ao encontro dos outros e de si mesmo.

Percebe-se, assim, a importância da dança no ensino; dança que, para ser ensinada, precisa de ser, não só entendida, como também vivenciada, não só explicada, como também experimentada, permitindo, assim, com a libertaçāo das emoções, a emergência de outras formas de conhecimento", mais próximas da realidade das nossas vidas. Isto implica o mesmo tipo de ressocialização, de aculturação invertida, que a antropologia reclama para a procura da verdade científica. Uma ressocialização que passa pelos movimentos do corpo - um corpo bem assente na terra, antes de atingir as alturas da alma - , e que se reaproxima, neste diálogo restabelecido entre o nosso húmus e os céus, do ponto fulcral de onde emana toda a criatividade humana.

E nesta luta contra o que fez de nós seres amnésicos, amnésicos da nossa pertença simultânea ao chão da terra e ao éter dos espaços estelares, a primeira viagem que, como ciência, a antropologia vai exigir, será uma viagem que nos leve a subir a corrente do tempo e a percorrer os espaços infinitos; uma viagem crítica e comparativa, portanto, à procura das raízes das primeiras formas das nossas elevações e das nossas subjugações, estabelecendo genealogias, mapeando caminhos, à procura das marcas que ficaram inscritas na nossa carne e na nossa alma. Esta viagem, aliás, de

- Como escrevem Federica Calviso Prina c Maurizio Padovan (2000) no seu livro intitulado A Dança no ensino obrigatório: "Reviver mentalmente uma imagem motora (uma parte da dança ou uma coreografía inteira), além de contribuir para a melhoria da já citada capacidade de memorização, desenvolve al capacidade de construir modelos e, em particular, a representaçāo mental de situaçōes dinâmicas." (p. 9)

${ }^{5}$ Do chefe Luther Standing Bear, algumas palavras esclarecedoras: "O Lakota era um verdadeiro amante da natureza. Amava a terra e todas as coisas da terra, e esse afecto crescia nele com a idade. Os idosos chegavam literalmente a amar o solo; sentavam-se ou repousavam na terra $\mathrm{com}$ o sentimento de se aproximarem das forças materiais. Era bom para a pele o contacto com a terra, e as pessoas idosas gostavam de tirar as mocassinas e andar de pés descalços sobre a terra sagrada. (...) O solo suavizava, fortificava, lavava e curava. É por isso que o velho índio se afinca ao solo, em vez de se separar das forças da vida. Para ele, sentar-se ou deitar-se assim consiste em poder pensar mais profundamente e em sentir mais vivamente; contempla assim mais claramente os mistérios da vida e sentese mais próximo das forças vivas que o envolvem ... ." in Teri Mc Luhan (1992), A fala do índio. Alto-retrato da vida dos índios da América do Norte. 
modo nada surpreendente mas todo pedagógico - a viagem que constitui uma fuga de si mesmo não resulta -, reaproximar-nos-á das tensões do nosso presente, tensões ainda não suficientemente esclarecidas, que a contemporaneidade questiona, por causa dos sulcos que cavou em nós, e de que a dança actual, nas suas tentativas de emancipação e nos seus debates, se torna uma testemunha privilegiada.

As primeiras cenas de um filme emblemático da história do cinema musical, Shall We Dance [1937], em que a dança constitui o argumento principal, podem constituir um passo esclarecedor neste caminho. Neste filme, Fred Astaire, que George Balanchine considerava o dançarino mais inteligente, mais inventivo e mais elegante do nosso tempo, questiona a codificaçāo rígicla da arte de dançar. No início do filme, de modo um tanto caricatural, as bailarinas, em pontas nas suas sapatilhas, giram, em voltas contínuas, de braços erguidos em arco de abóbada, todas parecidas nos seus corpetes e tutus brancos, como marionetas nas mãos do seu "maître de ballet". Depois, todas, alinhadas em várias filas e deslocando-se em conjunto, de um lado para o outro, mimam, repetidamente, "ora um rio, ora um regato". Entra o dono da companhia, com ar severo e aborrecido, procurando o bailarino-estrela, Petrov (Fred Astaire), o qual, segundo o "maître de ballet", está a treinar um salto na sala ao lado. Quando o dono da companhia abre a porta, fica estarrecido: Petrov está a praticar sapateado. O dono, zangado, pergunta: "O que está a fazer?" Petrov responde: "Estou a divertir-me". O dono exclama: "O grande Petrov não dança para se divertir!" Depois o dono interroga o bailarino para saber de onde provém este "ruído horrível" dos sapatos, e Petrov mostra a peça de metal fixada na sola. "Sacrilégio!", exclama o dono da companhia. Mas imediatamente Petrov mostra que sabe fazer o "grand jeté", de maneira perfeita, segundo as regras canónicas da tradiçāo clássica; no entanto, diz ser mais eficaz executá-lo em forma de sapateado. Para o dono: "Isto não é arte! Proíbo-o." Petrov propõe, então, combinar a técnica do bailado com o calor e a paixão desta outra forma de dançar.

É assim que o cinema, numa comédia musical hollywoodiana, dava conta, em 1937, da rebelião contra a rigidez da tradição clássica na dança, rebeliāo que, embora tendo tido, no século XIX, um precursor francês na pessoa de François Delsarte, só veio a manifestar-se plenamente no século XX, primeiro nos Estados Unidos da América e, posteriormente, na Europa. Que explicação dar a esta constestação, que tantas repercussões 
terá na história da dança, como também poderá ter nos sistemas educativos e cognitivos das nossas sociedades', e de cujas consequências ainda não suspeitamos na totalidade? É que o movimento do conhecimento não se compadece com uma simples figuração da realidade, com uma simples mimesis que se queira isenta de projecções subjectivas, e inserida em formas institucionais destinadas a conferir-Ihe o selo da validade, e assim a manter. A exigência primeira será, então, a de restituir às nossas práticas a consciência do seu substrato histórico. Voltemos, pois, às nossas raízes.

Em 1668, Michel de Pure, capelão do rei Luís XIV, que assiduamente assistia aos diferentes espectáculos apresentados na Corte - e nomeadamente aos bailados, no seu apogeu na segunda metade do século XVII -, produziu uma obra, intitulada Idée des spectacles anciens et nouveaux, na qual fez o inventário dos diferentes elementos que entram na composição dos espectáculos: temas e narrativas, músicas e instrumentos, passos e figuras, vestuário e máscaras, maquinaria e cenário. É um tratado, com tudo o que isso implica nessa época de classicismo e cartesianismo. Assim, se, por um lado, define como objectivo primordial do espectáculo "agradar aos olhos", estabelece, por outro lado, contrariamente à exuberância e ausência de constrangimentos dos bailados de Luís XIII, um conjunto de regras rígidas na execuçāo das obras e no comportamento dos artistas: conveniência, propriedade, justeza, regularidade, método e clareza. E aproveita para definir, da maneira mais explícita, o que se deve entender por "belle danse": "A dança que se nomeia «bela», que consiste num andar simples, respeitando bem o passo, e mantendo tempos regulares e justos, é sempre a mais majestuosa, e denota a pessoa de qualidade e, o que tem mais valor ainda, a modéstia e a virtude." Este conceito, construído à semelhança de diferentes expressões de mesma conotação, como, por exemplo "le bel usage" no domínio da língua, ou ainda, "les belles lettres" no da literatura, e "le beau monde" no da sociedade, é ca-

"Friedrich Nietzsche (1987) em A gaia ciência, enfatizou a importância da dança para o pensamento: “ Não pertencemos àqueles que só pensam no meio dos livros e cuja ideia para nascer espera pelos impulsos do impresso; o nosso costume é pensar ao ar livre, caminhando, saltando, subindo, dançando (...). O nosso primeiro movimento, para ajuizar de um livro, ou de um lomem, ou de uma música, é perguntar-nos: Sabe caminhar? Melhor ainda: sabe dançar?" (p. 274) 
racterístico de uma maneira de entender a arte a partir de critérios simultaneamente morais, sociais e estéticos, em que os códigos de comportamento aristocráticos serviam de matriz referencial.

Esta concepção da bela dança adequava-se, de maneira particularmente feliz, aos propósitos de Luís XIV que, ao criar a Academia Real de Dança, em 1662, pretendia restabelecer a arte da dança na sua primeira perfeição e desenvolvê-la. Desenvolvê-la porque, como diz o monarca, no texto que oficializa a responsabilidade académica na formulaçāo e na preservação das regras que a dança deve respeitar: a Arte da Dança foi sempre reconhecida como uma das mais honestas e mais necessárias para formar o corpo e dar-lhe as primeiras e mais naturais disposições para toda a espécie de exercícios, entre outros o das armas, e, por conseguinte, como uma das mais vantajosas e úteis para a Nobreza, "a nossa e as outras que têm a honra de estar colocadas na nossa presença". Mas também restabelecê-la na sua primeira perfeição, porque, como se diz no mesmo texto, foram introduzidos nesta Arte, como em todas as outras, durante as desordens e a confusão das últimas guerras, abusos capazes de a levar a uma ruína irreparável.

Este controlo do Estado sobre a dança, num contexto cultural em que a modernidade europeia procede à geometrização do homem e à sua inscrição progressiva em grandes corpos arregimentados, na preparação da guerra como na organização do trabalho, inaugura uma codificaçāo institucional de regras e esquemas de movimento que vão deixar, para o comum dos mortais, um espaço cada vez mais reduzido e limitativo para a criatividade poética e para a expressão da afectividade e das emoções. É, como nota Norbert Elias (1973), o resultado de um processo de civilização dos costumes, que se edifica na base da mutilação dos nossos impulsos instintivos. E este processo, que se inicia nos séculos XV e XVI, marca igualmente a emergência progressiva do homem da modernidade $\mathrm{e}$ dos valores burgueses que a acompanham.

Para o burguês, o trabalho torna-se um dever, uma virtude, uma profissão, e a melhor maneira de dar sentido à sua vida. Os animais simbólicos da nobreza (o leão, o lobo, o urso, a águia, ...) são substituídos pelos da burguesia (a formiga, o escaravelho, a abelha, o esquilo, ...). E o corpo, inicialmente órgão de prazer, é transformado em órgão de performance. A civilização ocidental procura, antes de tudo, estabelecer o seu poder sobre a natureza, e sobre os que a estudam e transformam, e vai 
desenvolver o seu saber e o seu saber-fazer com uma finalidade de dominação e de exploraçāo do mundo das coisas e, depois, dos seres vivos?

É por isso que, numa obra na qual procura as condições de libertação da dança e do movimento, Adolfo Andrade (1988) critica o seu passado e coloca, na base da tradição académica, o espírito de obediência ao poder. Como nas formaçōes militares, as deslocações dos bailarinos formam figuras geométricas no espaço. Estas deslocações são impostas do exterior com o objectivo de formar uma unidade de corpo. Nestas formações geométricas, todas as relações entre os bailarinos são comandadas à distância pelo coreógrafo. Este último exerce um poder absoluto, como um monarca, e nenhum bailarino pode nem deve deslocar-se sem a sua decisão. Também nas escolas é aplicada esta estrita geometria imposta do exterior. Certos movimentos eram, aliás, executados sem tomar em consideraçāo o sentido das articulações e das condições anatómicas. Há, pois, tanto na formaçāo dos bailarinos como na dos militares, uma vontade de ordem em que os indivíduos são alinhados, "quadrilhados" e hierarquizados num condicionamento geométrico rígido. As diferenças entre a ginástica rítmica, que prepara os militares, e o academismo da dança, que forma os bailarinos, deixam de ser, portanto, diferenças de essência.

É uma mesma e única razão instrumental, a que preside a formas educativas em tudo semelhantes quando se trata de preparar os corpos, e de sujeitar os espíritos, numa lógica funcional de hierarquização da sociedade para fins de hegemonia. Na mesma perspectiva, o paradigma da preparação física, tão prezado pelas nossas sociedades e pelos nossos sistemas de ensino, por se ajustar, de maneira tão harmoniosa, à nova ordem votada ao trabalho, tornar-se-á a actividade desportiva. Como mostra Heloisa Bruhns (1999), a correspondência é notória entre os valores vinculados ao desporto, tais como a exclusão, o consumismo, a dominação, a acumulação, e a sociedade que os evidencia com um grau significativo de importância.

'Edgar Morin (1990), em Science avec conscience " mostra como a experimentação científica constitui por si mesma uma técnica de manipulação e como o desenvolvimento das ciências experimentais desenvolve os poderes manipuladores da ciência sobre as coisas físicas e os seres vivos." (p.18) 
E é neste mesmo contexto que se instaura uma Ideia da dança, etnoe europeiocentrista, focalizada no espectáculo e no bailado, que a torna profissional $^{8}$, e que faz resvalar para formas subalternas, senão inconvenientes, as suas expressōes populares, exóticas, lúdicas, e conviviais". Tudo o que não se coaduna com a sacralidade da ordem social, e com a solenidade exigida pelos seus ceremoniais - embora se pretenda ter acabado com os mitos e os seus ritos, com o sagrado e as suas manifestações, e determinar tudo em função de critérios exclusivamente pragmáticos e, por isso mesmo, racionais -, torna-se objecto de várias formas, explícitas ou disfarçadas, de proibição. Entende-se melhor, agora, as razões pelas quais, tanto pelos efeitos teóricos que podem produzir numa releitura crítica da história, como nos efeitos práticos de desbravamento de novos terrenos e novas metodologias para a educação e o ensino, e, em particular, para o ensino da antropologia, as "outras danças" são redescobertas e revalorizadas pelo movimento contemporâneo. Recentrar a gravidade do corpo e do espírito ${ }^{10}$, procurar novos movimentos e novos pensamentos, cru-

"Uma obra coreográfica de M. Bennett, A Chorus Line, realizada em 1975, em que a dança veicula as emoções das personagens, segue o desenrolar de uma audição, e ilustra, com sentido crítico, a disciplina e a devoção de que o bailarino deve fazer mostras no seu trabalho. O tema foi, posteriormente, adaptado ao cinema por Richard Attenborough, em 1985, insistindo no carácter impiedoso do processo de selecção.

" Pierre Lory (1999) mostra, na sua introdução à obra colectiva Danse et spiritualité. L'ivresse' des origines, sob a direcção de France Schott-Billmann, como a evoluçāo das danças, no Ocidente, manifesta uma nova maneira de encarar o corpo. Às danças de origem popular, fortemente marteładas, sucedern coreografias mais ligeiras, mais aéreas, produzidas nas classes superiores da sociedade. O centro de gravidade do corpo eleva-se; os gestos simples, naturais e repetitivos das danças tradicionais sāo substituídos por movimentos mais complicados, relacionados com ritmos musicais cada vez mais subtis. Progressivamente instala-se o bailado clássico, em que a perfeição gestual é magnificada e o vivido emocional colocado em segundo plano. A dança torna-se uma competência antes de tudo formal, o corpo sendo inteiramente submetido às decisōes do espírito, mediante treinos e sacrifícios às vezes pesados.

"O conceito de enraizamento, tal como o define a análise bioenergética - por exemplo Alexander Lowen (1983), em La pewr de vive -, é, aqui, incontornável. Lembremos que, por enraizamento, se entende a conexāo energética que se estabelece entre os pés de uma pessoa e a terra ou o solo. Isto reflete o quantum de energia ou de sensação que a pessoa deixa penetrar na parte inferior do seu corpo. E, como as experiências vividas são estruturadas no corpo, é possível ler a história da pessoa, c as suas perturbaçōes emocionais, nas suas expressões somáticas. Este conhecimento pode ser aproveitado para aju- 
zar diferentes géneros e estilos, reencontrar outras culturas e sociedades, reapropriar-se do quotidiano e do banal, serão muitas das maneiras, na dança, de reinventar o mundo e a vida.

É por isso que, retomando uma distinção de Pascal, que opunha o espírito de fineza ao espírito de geometria, convém, hoje, tornar manifestas as formas mais subtis, e mais ocultas, de violência, que continuam, nas nossas sociedades, a limitar o potencial expressivo do ser humano, tanto a nível social como no plano individual. E particularmente na dança, porque, se a dança, de facto, não é uma panaceia, e pode, como qualquer fenómeno cultural de carácter relacional, surtir efeitos contrastados - dela podendo resultar uma relação de subjugação que jugula as capacidades criativas e expressivas do ser humano; mas dela podendo, igualmente, resultar um efeito catártico, de libertação das energias individuais e comunais -, na dança, particularmente, as práticas emancipadoras são transversais em relação a todas as dimensões essenciais da vida humana: físicas e psíquicas; conscientes e inconscientes; cognitivas e afectivas; individuais e colectivas. Para isso, ela precisa, tão só, de escapar ao controlo das suas formas mais restritivas de socialização e de educação.

Mesmo assim, há, na dança, uma dimensão de transcendência que lhe é imanente, e que lhe permite, em grande parte, superar, por si mesma, independentemente dos seus contextos mais restritos, mais elitistas e mais académicos, os efeitos de fragmentação que caracterizam a ordem social actual. É a razão pela qual, quando assistimos a um "pas de deux" de um bailado clássico, continuamos a vibrar, emocionalmente, com o sentimento de ter vivido um momento de beleza inefável, e de aproximação a uma realidade mais subtil. É que a nossa época, atolada num materialismo sumário, de consumo reificado, que vive à sombra das torres dos grandes centros comerciais e financeiros, precisa da elevação que as grandes catedrais já nāo the podem proporcionar. Se, para a maioria, o corpo já não se pode elevar, pelo menos que se eleve ainda a alma ao espectáculo do "grand jeté", que desafia as leis da gravidade, ou das voltas múltiplas, que anulam a sensação do tempo que passa, inexoravelmente.

dar a pessoa a estabelecer um contacto mais firme com o solo, a aumentar a sua energia, a alargar e aprofundar a percepção que tem de si mesma. Percebe-se, agora, como, na dança contemporânea, este saber é aplicado. E como, também, se opera o reencontro com outras culturas, mais conscientes da importância do contacto com a terra. 
É o que percebeu Paul Valéry (1945), quando, a seguir à primeira guerra mundial, criticando os seres humanos por não saberem o que fazem, mas o fazerem com o poder dos deuses, escreveu, em forma de diálogo, um texto-chave, L'âme et la clanse, que permite a compreensão do drama existencial do homem do século $\mathrm{XX}$ : nas miragens de um espaço-tempo que se domina cada vez mais e melhor pela máquina, a alma humana perdeu-se. E, pela boca de Sócrates, Valéry coloca duas questōes cujo alcance antropológico está ainda longe de ter sido plenamente compreendido: "o que é verdadeiramente a dança?", e "o que é que nos podem dizer os seus passos?" Questōes cuja prioridade actual só se entende quando sabemos que, no mesmo escrito, Sócrates, o filósofo da maiêutica que procura incomodar, força Erixímaco, o médico do naturalismo que pretende curar, a reconhecer a ineficácia dos remédios habituais que utiliza para combater a doença: é que o mal humano é mais profundo do que aquilo que a farmacopeia, com o seu arsenal, consegue curar.

De facto, o melhor do ser humano não se esgota, como uma finalidade em si mesma, em técnicas e ciências que visem superar as imposições das leis da natureza. Sem o questionamento ético do seu valor humano e social, sem o sentido estético da sua aproximação ao outro, o melhoramento contínuo das técnicas e das ciências, como resultado de uma mística do progresso ao serviço do domínio material e espiritual do mundo, redunda em formas extremas de barbárie.

Depois do derrube das grandes referências espirituais univocas e da reconfiguração das crenças à volta do corporeísmo actual, a dança e as interrogações que ela suscita e requer, manifestam tanto a necessidade do gesto técnico como as suas insuficiências; tanto a importância do pensamento analítico como as suas limitaçōes; tanto o valor do despertar ético como as suas lacunas; tanto o ideal da vocação artística como as suas fragilidades. O retorno à terra, depois dos excessos de elevação dos corpos destinados a compensar o esvaziamento progressivo das almas, não quer dizer o abandono da ideia de um mundo melhor. Mas quer dizer, e isso sim, de modo claro, que um mundo melhor só se constrói a partir de um novo lugar incandescente em que se volte a operar a fusão das qualidades essenciais que a nossa civilização separou no homem da modernidade: o corpo e o espírito; a sensibilidade e a inteligência; a paixão e a razão.

Esta separação é o que as coreografias mais recentes contestam, tanto nas suas formas mais estruturadas e repetíveis, como em happenings 
e performances mais espontâneos e participativos, denunciando, simultaneamente, as raízes sociais e culturais do afastamento progressivo entre a dança e a sociedade, entre a personalidade e a afectividade" mundo. E esta separação é o que constitui, sem dúvida nenhuma, a razão essencial pela qual a antropologia da dança, ao mesmo tempo que analisa as formas coreográficas dos outros, não pode deixar de as reavaliar, no negativo das texturas impensadas da geometrização modernista, e no positivo das expressões manifestas da contestação contemporânea.

A palavra da antropologia, hoje, é cristalina: a elevaçāo humana não resulta quando a afirmação de uns depende da negação dos outros. Daí a importância da dança que, ainda segundo Valéry (1945), nos elucida acerca do que fazemos, mostrando claramente às nossas almas o que os nossos corpos cegamente cumprem.

\section{Bibliografia}

Andrade, A. 1988. Pour une danse enfin libérée. Paris, Laffont.

Bruluns, H. 1999. O corpo parceiro e o corpo adversário. São Paulo, Papirus.

Devereux, G. 1972. Essais d'ethopsychiatrie générale. Paris, Gallimard.

Elias, N. 1973. La Civilisation des moeurs. Paris, Calmann-Lévy.

Jaccard, R. 1975. L'exil intérieur: Schizoüdie et civilisation. Paris, P.U.F.

Legendre, P. 2000. La passion d'être un autre. Étude pour la danse. Paris, Seuil.

Lombard, J. 1984. L'enseignement de l'anthropologie: un bilan comparatif.

Revue internationale des sciences sociales, 36(4): 749-759.

Lory, P. 1999. Introduction. In: Schott-Billmann, F. (dir.) Danse et spiritualité. Paris, Noêsis : 9-20.

Lowen, A. 1983. La peur de vivre. Paris, Épi.

Mc Luhan, T. 1992. A fala do indio. Auto-retrato da vida dos indios da América do Norte. Lisboa, Fenda.

Morin, E. 1990. Science avec conscience. Paris, Seuil.

" Roland Jaccard (1975), no seu livro L'exil imérieur: Schizoìdie et civilisation, lembra como a distância, a reserva, a frieza são comportamentos que possuem um valor exemplar nas nossas sociedades, e traduzem, atrás desta máscara de soberana indiferença, um profundo sentimento de insegurança e de desprezo por si mesmo. 
Nietzsche, F. 1987. A gaia ciência. Lisboa, Guimarães editores.

Prina, F; Padovan, M. 2000. A dança no ensino obrigatório. Lisboa, Fundação Calouste Gulbenkian.

Thuillier, P. 1995. La Grande Implosion. Paris, Fayard.

Valéry, P. 1945. L'âme et la danse. Paris, Gallimard. 